\begin{tabular}{|l|r|}
\hline \multicolumn{1}{|c|}{ S sciendo } & \begin{tabular}{c} 
NCF $\begin{array}{l}\text { Nordic } \\
\text { Concrete } \\
\text { Federation }\end{array}$ \\
\hline $\begin{array}{l}\text { (C) Article authors. This is an open access article distributed under } \\
\text { the Creative Commons Attribution-NonCommercial-NoDerivs } \\
\text { licens. (http://creaticecommons.org/licenses/by.nc-nd/3.0/). }\end{array}$
\end{tabular} \\
\hline & $\begin{array}{r}\text { ISSN online 2545-2819 } \\
\text { ISSN print } \quad \text { 0800-6377 }\end{array}$ \\
DOI: $10.2478 /$ ncr-2019-0014 & $\begin{array}{r}\text { Received: March 14, 2019 } \\
\text { Revision received: Aug. 28, 2019 }\end{array}$ \\
& Accepted: Sept. 30, 2019 \\
\hline
\end{tabular}

\title{
In-Situ and Laboratory Investigation on Leaching and Effects of Early Curing of Shotcrete
}

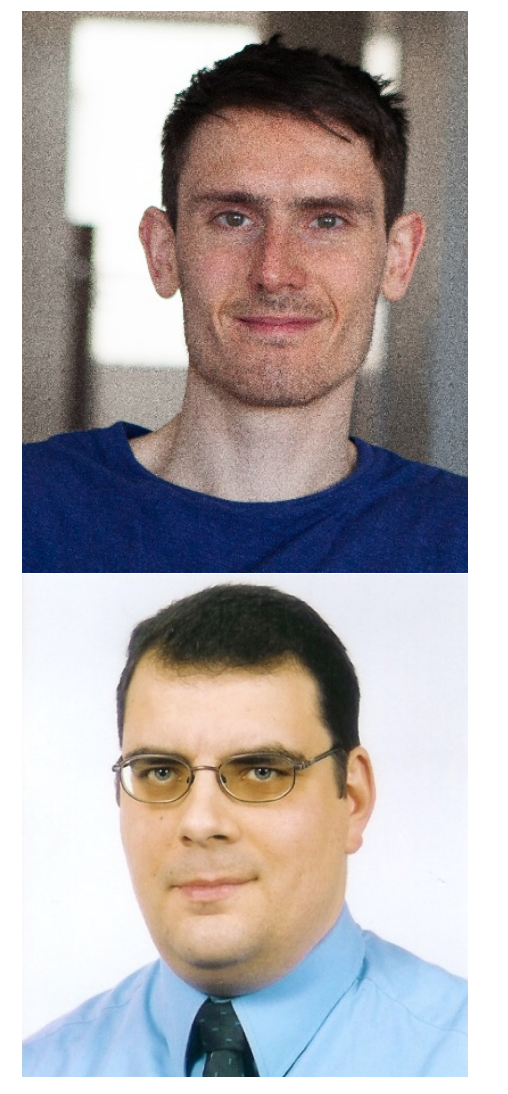

\author{
Andreas Sjölander \\ Tech. Licentiate, PhD student \\ KTH Royal Institute of Technology \\ Division of Concrete Structures \\ Brinellvägen 23, 10044 Stockholm \\ andreas.sjolander@byv.kth.se
}

\author{
Anders Ansell \\ Ph.D., Professor \\ KTH Royal Institute of Technology \\ Division of Concrete Structures \\ Brinellvägen 23, 10044 Stockholm \\ anders.ansell@byv.kth.se
}

\begin{abstract}
During the construction of a rock tunnel in Stockholm, several sections with leaching shotcrete (sprayed concrete) were found one year after the spraying was completed. An investigation was therefore conducted, and its results are presented in this paper. The amount of leaching after such a short time indicated that a one-sided water pressure existed in combination with a permeable shotcrete. The reason for the water pressure was likely a partly unsuccessful grouting that created sections with leaking water. The permeable shotcrete could be a combined result of insufficient curing and the use of accelerators, and the effect of in-situ curing was therefore investigated. A total of six slabs were sprayed and cured under different conditions in the tunnel. Test results according to standards indicated that curing has no significant effect on the development of mechanical strength or water penetration through the shotcrete. However, this is believed to be a
\end{abstract}


result of the test method rather than the non-existing effect of curing. Lastly, some modifications to the test standard were proposed for future studies of in-situ curing.

Key words: shotcrete, curing, experiments, investigation, testing.

1.

\section{INTRODUCTION}

Shotcrete (sprayed concrete) is often used as permanent rock support in the Nordic countries. Through adhesion, the shotcrete bonds to the rock surface and creates a composite support system with the rock and sometimes also together with rock bolts. Previous studies by e.g. Malmgren et al. [1] and Ansell [2] have shown that shotcrete subjected to drying is prone to cracking. Shotcrete used as rock support is normally reinforced with a type and amount of steel fibres that results in a strain-softening behaviour. This means that during a four-point bending test, the fibre reinforced shotcrete (FRS) is unable to redistribute the force after the first crack appears and further loading leads to propagation of the existing crack until failure. However, it has been shown both numerically by Sjölander and Ansell [3] and experimentally by Carlswärd [4], that if the shotcrete has a continuous bond to a stiff substrate, e.g. concrete or rock, a pattern of fine cracks develop instead of one wide. A continuous bond between the shotcrete and rock is therefore of great importance. If cracks form early after spraying, i.e. during the construction of the tunnel, further loading caused by either deformation of the rock or by shrinkage of the shotcrete could lead to failure of the interface between shotcrete and rock. This will reduce the structural capacity of the support and could also lead to downfall of shotcrete.

During the construction of a motorway tunnel in Stockholm, sections with leaching shotcrete were found one year after completing spraying, see examples in Figure 1. The extent of the leaching was more severe in these sections compared to the rest of the tunnel. Leaching is a deterioration process in which the calcium hydroxide $(\mathrm{CH})$ in the concrete is dissolved in water and transported to the surface. This occurs through cracks or through a very porous concrete and is characterized by a white precipitation on the surface $[5,6]$. Due to the extent of leaching at such an early age, it was believed that this had occurred through cracks in the shotcrete and that insufficient curing of the shotcrete was the reason for the formation of cracks. An investigation was conducted to determine: $i$ ) the presence and size of cracks in the leached areas, ii) the cause of leaching and iii) if curing of young shotcrete effects its mechanical strength and bond strength to the rock.

The investigation was initiated by Trafikverket (Swedish Transport Administration) and planned and carried out in collaboration with the Division of Concrete Structures at KTH Royal Institute of Technology and ÅF Infrastructure AB. Here, the results from this investigation are presented and structured in the following way: First, a theoretical background to the development and deterioration of concrete is given, together with some considerations regarding thin shotcrete structures in tunnel environments. Then, results from the in-situ and experimental investigation is presented followed by a discussion and conclusions. 

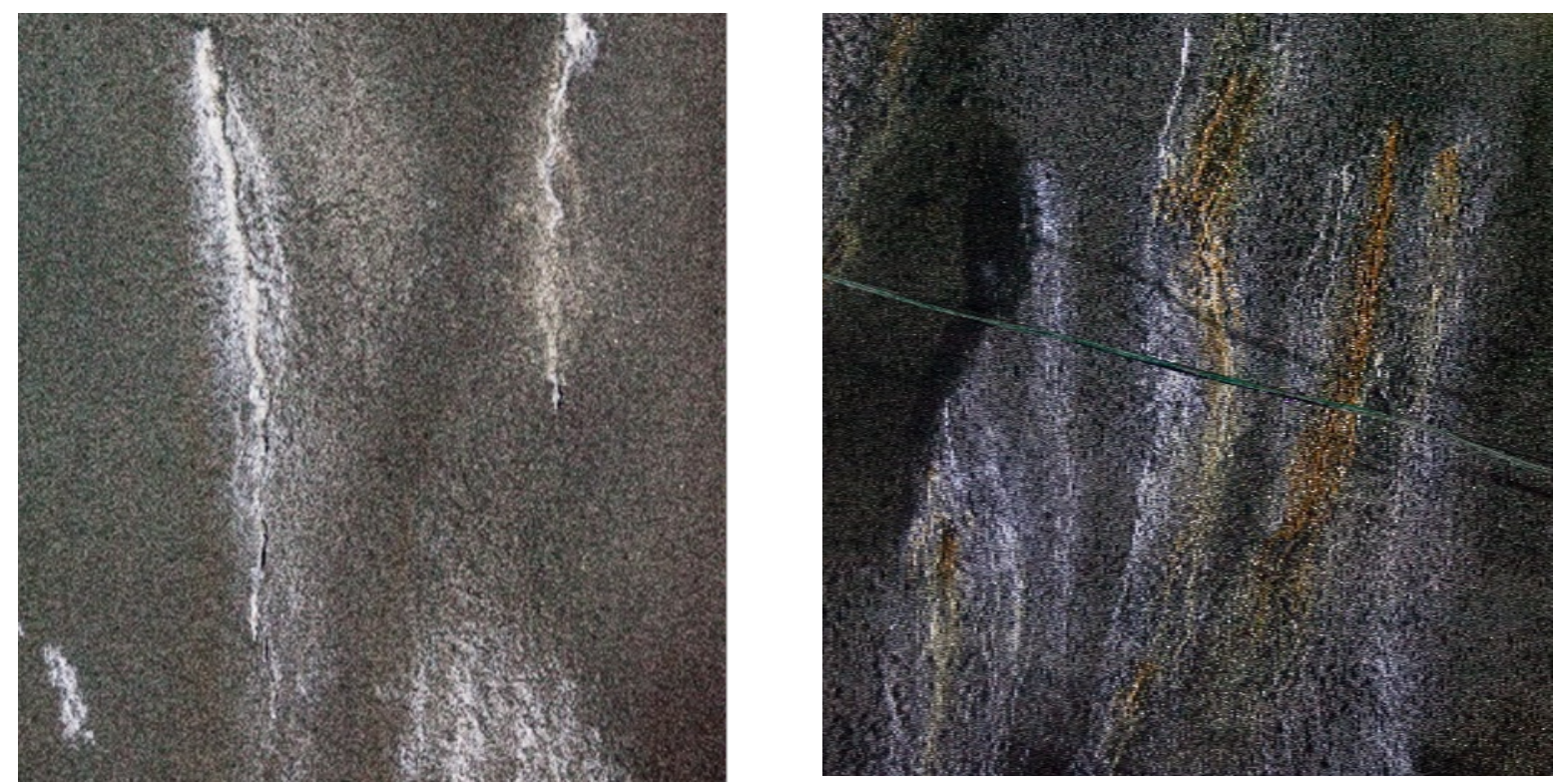

Figure 1 - Examples of leaching in shotcrete one year after completion.

\section{DEVELOPMENT OF SHOTCRETE STRENGTH}

Concrete and shotcrete share many similarities and therefore, this section starts with a general description of hydration and curing of concrete. After that, leaching is briefly explained and followed by some special considerations regarding curing of thin shotcrete structures.

\section{1}

\section{Hydration of concrete}

During hydration, water and cement reacts to create the cement paste, which, is an exothermic reaction that generates heat and consumes water [7]. The hydrated product of cement and water occupies less space than the individual components which leaves a residual space, capillary pores, in the concrete [8]. As long as free water in the capillary pores is available, hydration continues which results in that the porosity decreases and the capillary system gets partly blocked by the solid products of hydration. The strength of the concrete is significantly increased when the porosity and size of the pores decrease while the ability to transport fluids and gases becomes reduced when the connection between the pores becomes blocked which increase the durability of the concrete [8]. When the relative humidity $(\mathrm{RH})$ in the capillary pores drops below an approximate level of $80 \%$, a significant decrease in the rate of hydration occurs [9].

\section{2}

\section{Curing of concrete}

From the preceding discussion, it is clear that concrete should be kept as saturated as possible to promote hydration and it is well known that its strength increases when hydrated in air with high relative humidity, see e.g. Neville [7]. Actions taken to promote hydration is referred to as curing. Concrete cast in-situ should be cured to reduce the risk of plastic shrinkage cracking and to promote the development of strength and durability of the surface $[7,10]$. In-situ curing is often stopped when a specified strength is reached and is performed in two different ways; by adding 
water or by preventing loss of water. Both methods have advantages and disadvantages and the curing method should be selected with respect to curing-efficacy and on-site conditions. In some cases, natural curing which means that no curing actions are taken, could be used. Then, the RH in the concrete should be kept at a minimum of $80 \%$ [7]. For this to occur, the driving forces that causes drying of the concrete should be minimized. This means that the RH of the ambient air should be at least $80 \%$, the temperature difference between concrete and ambient air should be kept low and the wind speed should be close to zero. In some cases, preventing the surface of the concrete from drying is sufficient. However, the relative humidity in the concrete is also affected by the water consumed by the chemical reactions with cement. This is called self-desiccation and means that even if drying is prevented, the relative humidity in the concrete drops if no water is added. This effect is more pronounced for mixes with lower water-cement (w/c) ratios, see e.g. Zhang et al. [11].

\section{3}

\section{Leaching of shotcrete}

During leaching, calcium hydroxide $(\mathrm{CH})$ is dissolved in water and transported through the material which results in an increased porosity and decrease in strength [6]. The leaching process is driven by either diffusion (slower process) or by the flow of water (faster process) [5]. When particles of $\mathrm{CH}$ reaches the surface, they react with carbon dioxide $\left(\mathrm{CO}_{2}\right)$ in the air and forms a white precipitation on the surface [5]. This is the characteristic indication of leaching through cracks, but the colour could vary since it depends on the content of dissolved products, see Figure 1. Internal leaching could not be directly observed but the increased internal porosity could increase the rate of other deteriorating mechanisms. Damage caused by internal leaching is therefore normally discovered in connection with damage caused by other deterioration mechanisms [12]. Besides the negative effects caused by leaching, the transportation of dissolved $\mathrm{CH}$ through cracks could, under certain conditions, result in self-healing of the cracks, see e.g. Tittelboom and de Belie [13] and Nijland et al. [14]. This would decrease or even stop the leaching process.

\subsection{Special considerations for thin shotcrete structures in tunnels}

The roof and walls in tunnels are often supported by a 50 to $150 \mathrm{~mm}$ thick FRS lining. Through adhesion to the rock and the use of accelerators that creates an immediate stiff structure, volumetric changes of shotcrete occur in a restrained structure. Shrinkage caused by drying or self-desiccation results therefore in internal stresses and possibly cracking. Furthermore, shrinkage in the stiff structure will according to Lagerblad et al. [15] also increase the porosity. For the road tunnels in Sweden, the exposure class for shotcrete is given in national standards [16]. In this part of the tunnel, the exposure class is set to XS2 due to corrosion from chlorides in sea-water and XF4 with respect to freeze/thaw cycles [17]. With a technical lifespan of 120 years, the maximum $\mathrm{w} / \mathrm{c}$ ratio is then, according to the Swedish national annex EN 1992-1-1 [18], limited to 0.45 . The shotcrete linings have a high surface/volume ratio which increases the rate of drying [8]. Furthermore, shotcrete is normally installed close to the tunnel front in which forced ventilation with high air flow is used after each blast to clean the air. The air flow is one of the factors that influence the rate of evaporation of water from the surface of the shotcrete. Both of these factor could increase the need of proper curing.

Studies on moisture movements in concrete, see e.g. Zhang et al. [11], have shown that the RH in the concrete at a depth of 30 to $50 \mathrm{~mm}$ in many cases is over $80 \%$. For thicker concrete structures, 
this means that curing normally affects the quality of the top surface, i.e. the cover of the reinforcement. However, for shotcrete with a thickness of $50 \mathrm{~mm}$, curing could have a more significant effect. Furthermore, when the shotcrete is subjected to deformation from the rock, or loaded by individual blocks, tensile stresses develops in the top surface of the shotcrete. It is therefore important that a sufficient strength has developed in this part of the shotcrete. Sometimes, it is argued that the RH in the tunnel is sufficiently high and that natural curing could be used. Nevertheless, according to Galan et al. [6], the natural curing of shotcrete could be insufficient. Especially, the outer layer of shotcrete will contain lower amounts of hydrated products and have a higher porosity compared to inner parts of the shotcrete. If natural curing should be used, continuous measurements of temperature and $\mathrm{RH}$ at the site should be conducted to show that additional curing is unnecessary.

\section{3. \\ IN-SITU AND EXPERIMENTAL INVESTIGATION}

In this section, methods and results from the in-situ and experimental investigation of shotcrete is presented. All experimental testing was performed according to the quality control program of the project which follows the governing standards.

\subsection{Composition of shotcrete}

In all tests, wet mixed shotcrete was used and its composition is presented in Table 1. This represents a common mix for shotcrete used as rock support.

Table 1 - Composition of shotcrete

\begin{tabular}{l|cl}
\multicolumn{1}{l}{ Denotation } & Value & Comment \\
\hline Quality & $\mathrm{C} 32 / 40$ & Quality normally used in Swedish tunnels. \\
Cement & CEM I - $42.5 \mathrm{~N}-\mathrm{SR} 3$ & Pure Portland cement. Sulphate resistant with $\mathrm{C}_{3} \mathrm{~A}<3 \%$ \\
D $_{\text {max }}$ & $8 \mathrm{~mm}$ & Max. size of aggregates. \\
Slump class & $\mathrm{S} 4$ & Slump from 160 to $210 \mathrm{~mm}$. \\
W/C ratio & 0.45 & Max. ratio between water and cement. \\
Exposure class & $\mathrm{XF} 4 / \mathrm{XS} 2$ & Decided with respect to environmental conditions. \\
Min. Air content & $5 \%$ & Air content in fresh shotcrete. \\
Fibres & & \\
Accelerator & $45 \mathrm{~kg} / \mathrm{m}^{3}$ & Amount of fibres. \\
& Varies & Depending on conditions during spraying. \\
\hline
\end{tabular}




\subsection{In-situ investigation of cracks}

Based on photos and a preliminary in-situ inspection of the shotcrete, some sections were selected for a detailed inspection. The primary theory was that leaching had occurred through cracks in the shotcrete and that this could have caused damage to the interface between shotcrete and rock. A skylift was used to get close to the surface. The bond was tested by striking the surface with a hammer and a crowbar and observing the sound. In all tested sections, no signs of bond failure could be detected. However, the utmost quality of the shotcrete was on many locations poor and broke on impact. On most locations this corresponded to a couple of millimetres of shotcrete. The shotcrete was visually inspected at hand-close range, but no cracks were found. This indicates that if crack exists, their length and width should be limited. Some of the sections with precipitation were still wet which indicates that the leaching process had not stopped. On these locations, the source of leaching seemed to be circular holes with a corresponding size to large aggregates. In the sections where the surface was dry, leaching could have occurred through cracks that where healed and closed during the process.

In Figure 2, three examples of leaching from three different sections (I to III) in the tunnel are shown. These sections are supported with 50 to $75 \mathrm{~mm}$ FRS in combination with systematic bolting with a bolt distance of $2.0 \mathrm{~m}$. In section $\mathrm{I}$, the precipitation has a rusty/brown colour. According to the geotechnical investigation of the rock for section I, water was leaking from two grouting holes in the area and from several joints in the rock which contained iron. This iron content is the most likely explanation for the colour of the precipitation. For section II, a 0.5 to 10 $\mathrm{mm}$ wide and clay filled joint crosses the entire tunnel. Water leaks from joints which seems to coincide with the section of leaching. In section III, a large area of leaching is visible in the roof of the tunnel. According to the geotechnical investigation, a 0.5 to $2.0 \mathrm{~mm}$ wide and dry rock joint runs along the roof of the tunnel. 


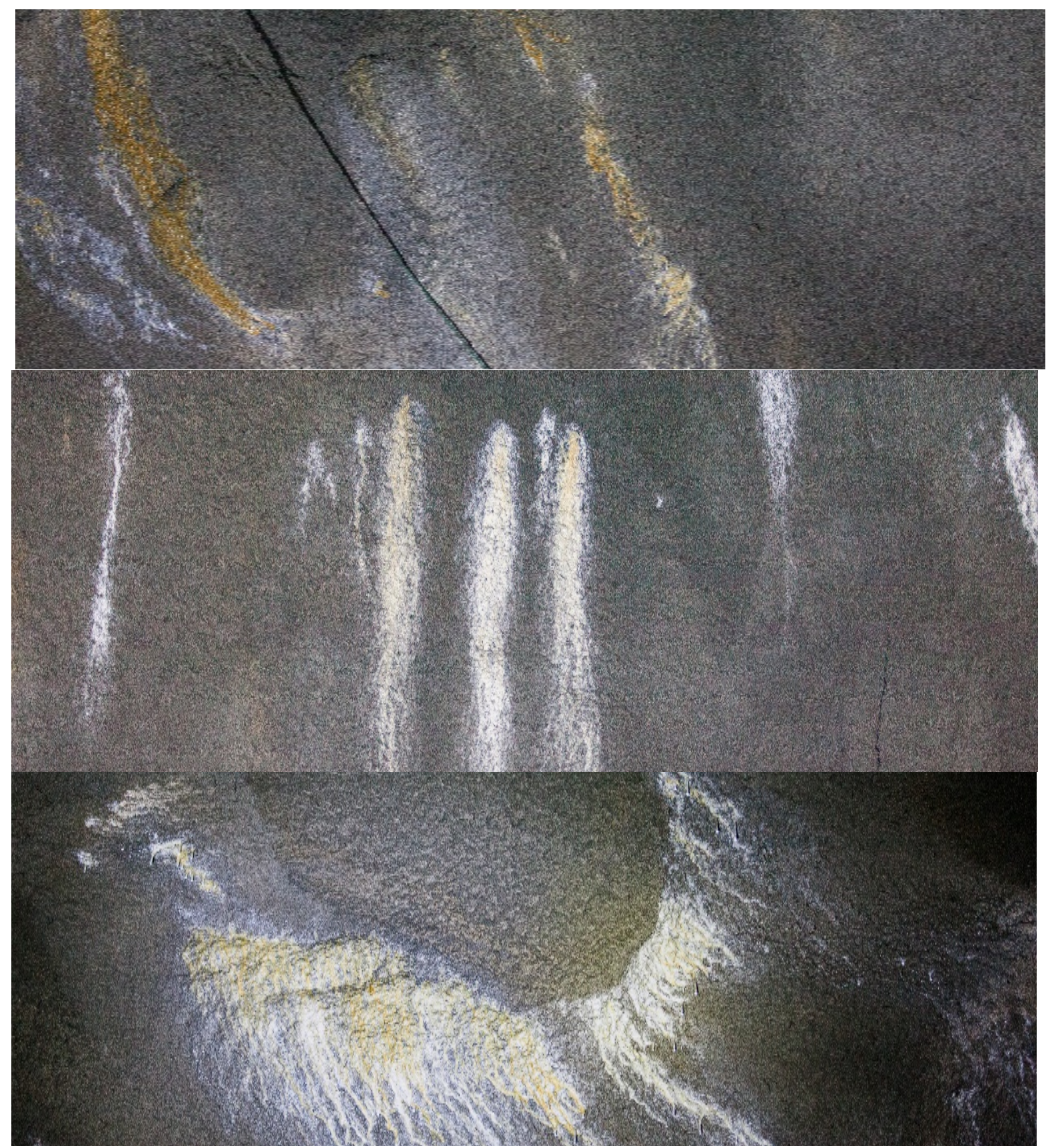

Figure 2 - From up to down, examples of leaching in section I-III.

\section{3}

\section{In-situ preparations of samples for testing}

The purpose of these experiment was to investigate if partial curing, i.e. adding water during a limited period during hydration, has any effect on the development of the mechanical strength of the shotcrete or the bond strength between shotcrete and rock. Shotcrete was sprayed into six $800 \times 600 \times 150 \mathrm{~mm}$ (length $\times$ width $\times$ height) wood moulds placed in a standing position in the tunnel, see Figure 3. The slabs were sprayed one by one using shotcrete from the same delivery truck. After spraying, the following scheme was applied:

- Slabs 1 to 3 were kept dry.

- Slab 4 was watered when the surface was considered to be dry. 
- Slabs 5 and 6, water was added every second hour.

A hose was used and each surface was sprayed with water for one minute. This scheme was kept for the first 48 hours after spraying. Thereafter, the slabs were removed from the moulds and placed at a different location in the tunnel in which they were kept for 26 days. During this time, no water was added and the original plan was to move the slabs to a dry location in the tunnel and place them side-by-side. Instead, the slabs were by mistake moved to another location in the tunnel where the slabs were stacked upon each other in groups of two. At this location, partial leaking of water occurred from the roof of the tunnel which led to that water dripped on limited areas on some of the slabs. The drying conditions during these 26 days was not optimal and this could have effects on the results. In addition to the moulds, three sections of shotcrete sprayed onto the rock were also monitored. The approximate size of each area was $2 \times 2 \mathrm{~m}$. The rock surface was cleaned by spraying water with the shotcrete robot prior to spraying shotcrete. No water was added to the shotcrete and after a minimum of 28 days of curing, the bond between shotcrete and rock was tested. It should be noted that the majority of the third section was wet during the first 48 hours due to leaking of water, see Figure 3. The experiments were performed during autumn in a location of the tunnel in which the temperature is rather constant. However, the temperature and RH were not monitored.

\section{4}

\section{Performed tests}

After 28 days of curing in the tunnel, all the slabs were transported to the Vattenfall R \& D laboratory in Älvkarleby where the following tests were performed:

- Compressive strength on cubes according to EN-12390-3:2009 (53 days after spraying) [19].

- Flexural and residual strength on beams according to EN-14488-3:2006 (58 days after spraying) [20].

- Water penetration test on cubes according to EN 12390-8: 2019 (58 days after spraying) [21].

- Bond test according to EN-14488-4:2005+A1:2008 (119 days after spraying) [22].

The storing conditions at Vattenfall $\mathrm{R} \& \mathrm{D}$ is unknown but their normal procedure is to store the slabs at around $+20^{\circ} \mathrm{C}$ and add water to the slabs upon arrival. After the test specimens are cut, they are stored at $+20^{\circ} \mathrm{C}$ and $\mathrm{RH} 65 \%$. Test specimens were prepared according to the above mentioned standards and the tests for compressive strength and water penetration were performed on cubes with dimensions $100 \mathrm{~mm}$ and $150 \mathrm{~mm}$, respectively. For the water penetration test, water pressure was applied towards the top surface, i.e. the rough surface. Testing of flexural and residual strength according to EN 14488-3 [20] is performed through four-point bending tests on beams with dimensions $500 \times 125 \times 75 \mathrm{~mm}$ (length $\times$ width $\times$ height). Beams are cut according to the arrangements shown in Figure 4 and during testing, the bottom uncut moulded face should be put in tension. All preparation of test samples and testing was performed according to standards 

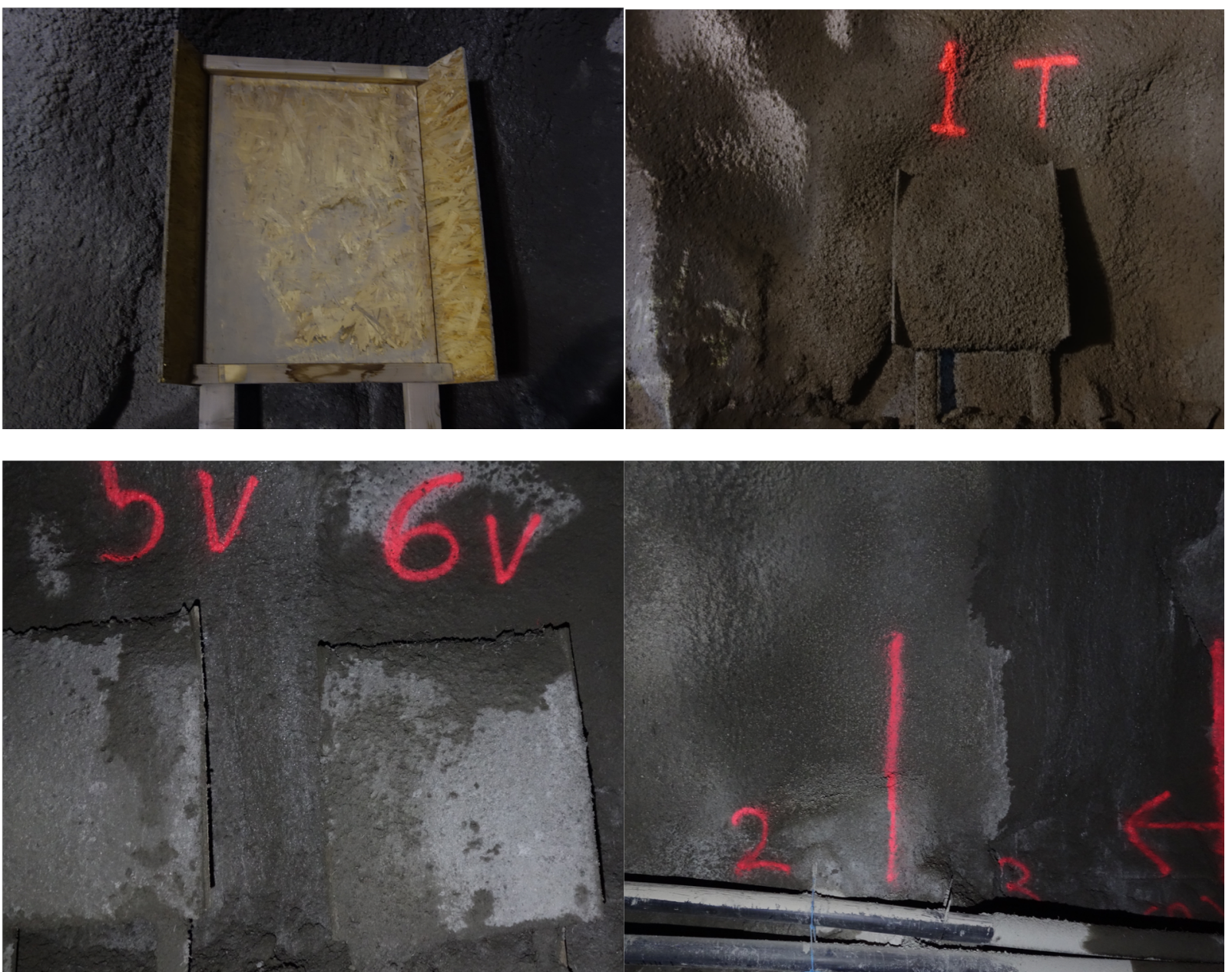

Figure 3 - From top to bottom, left to right i) mould for test samples, ii) marking after finished spraying, iii) drying process and iv) shotcrete sprayed on rock for bond test and extent of wet area at the third section.

and by qualified personnel. This means that the top surface of the slab was removed when preparing the samples for compressive and tensile tests. From each of the six slabs, three test samples were prepared for each test.

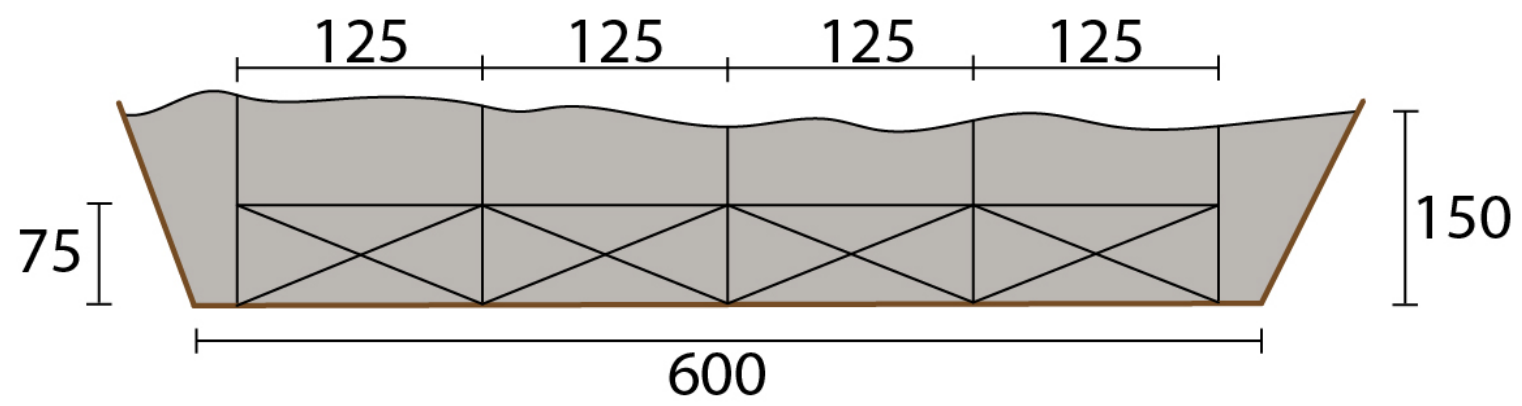

Figure 4 - Cutting arrangements for beams according to EN 14488-3 [20]. 
4. RESULTS

Results for compressive strength, water penetration, flexural and residual strength (for a deformation of $2 \mathrm{~mm}$ ) are shown in Figure 5. The results are presented for each slab and each bar represents the range of three results. For compressive strength and water penetration, there is a clear difference between the results for Slab 6 compared to the other five slabs. Water was added to this slab during the first 48 hours and in contrast to what is expected, the compressive strength is lower and the water penetration higher compared to the other slabs. However, for flexural and residual strength no unexpected difference exist between the slabs.

Tests of bond strength were performed at three locations at each section, i.e. a total of nine tests were performed. The results are presented in Table 2 . The requirements on bond strength in the project is $0.5 \mathrm{MPa}$ and according to the standard for testing [22], a valid result for bond strength requires that at least $80 \%$ of the fracture zone should be at the interface. Two failures should thereby be disregarded and out of the remaining seven tests, two results showed a lower bond strength than required.
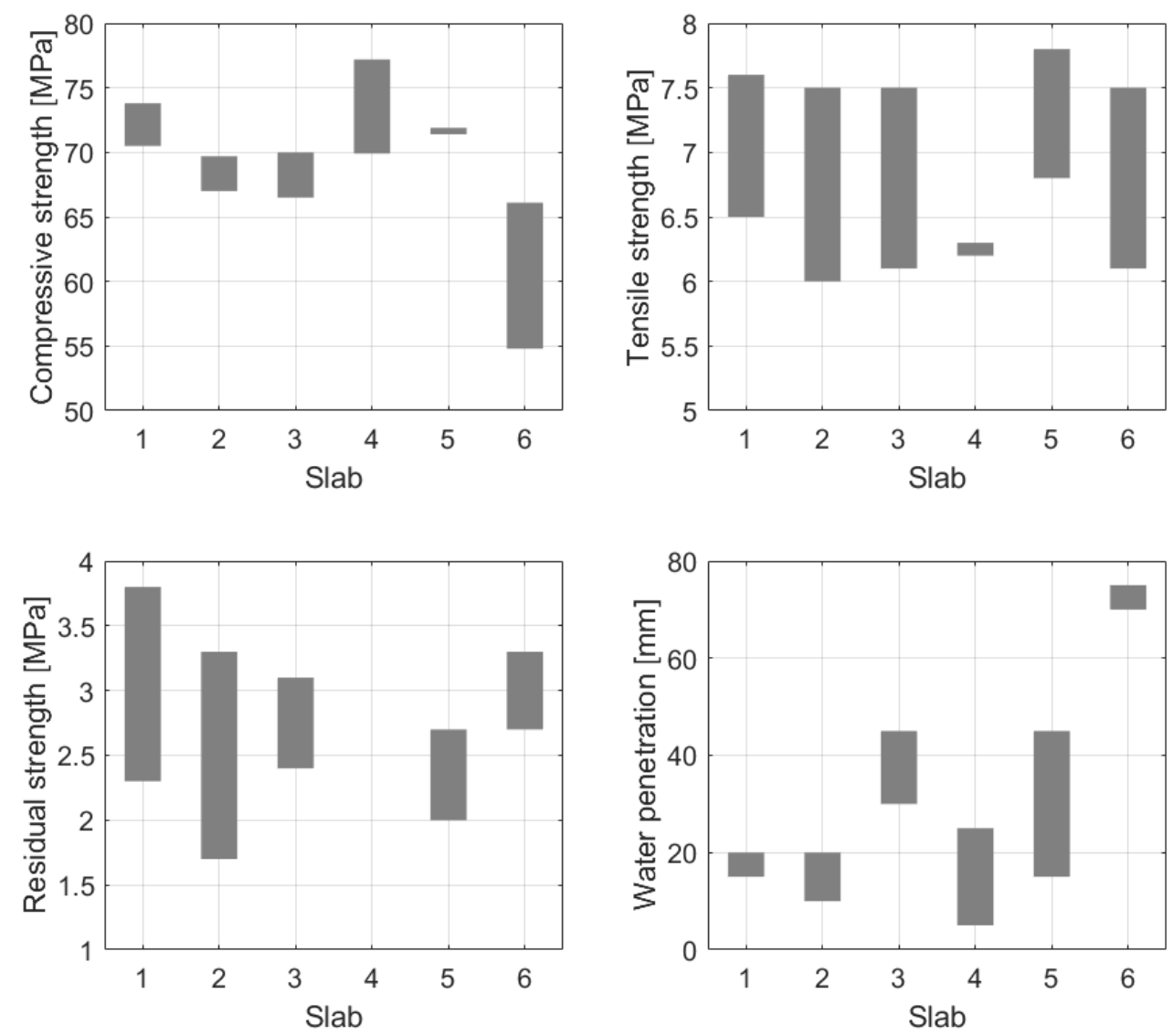

Figure 5 - Test results for compressive strength, water penetration, flexural strength and residual strength at a deformation of $2 \mathrm{~mm}$. Each bar represents the range of results for one slab. 
Table 2 - Bond strength from testing.

\begin{tabular}{|c|c|c|c|c|c|c|}
\hline \multirow[b]{2}{*}{ Test } & \multicolumn{2}{|l|}{ Section1 } & \multicolumn{2}{|l|}{ Section2 } & \multicolumn{2}{|l|}{ Section 3} \\
\hline & $\sigma_{\mathrm{ad}}[\mathrm{MPa}]$ & Fracture Zone & $\sigma_{\mathrm{ad}}[\mathrm{MPa}]$ & Fracture Zone & $\sigma_{\mathrm{ad}}[\mathrm{MPa}]$ & Fracture Zone \\
\hline 1 & 0.36 & $100 \%$ Interface & 0.22 & $100 \%$ Rock & 0.74 & $100 \%$ Interface \\
\hline 2 & 0.78 & $100 \%$ Interface & 0.31 & $100 \%$ Rock & 0.80 & $100 \%$ Interface \\
\hline 3 & 0.63 & $100 \%$ Interface & 0.19 & $100 \%$ Interface & 0.86 & $100 \%$ Interface \\
\hline Mean & 0.59 & & 0.24 & & 0.80 & \\
\hline
\end{tabular}

5. DISCUSSION

Below, the results from the in-situ and experimental investigation are discussed.

\section{$5.1 \quad$ Leaching of shotcrete}

In the studied sections, large areas of precipitation were found a short time after construction was finished. Leaching is a common deterioration process in concrete structures subjected to a onesided water pressure. However, the process is normally very slow and it often takes years before any visible signs of leaching can be seen on the surface. Due to the fast process shown here, the driving mechanism for leaching must have been water flowing through the shotcrete. The reason for the flowing water could be an unsuccessful pre-grouting of the rock, leaking from grout holes or from rock bolts. Water leaking from the rock and from grout holes was present at sections I and II, as shown in Figure 2. For section III, it looks like the precipitation has formed around a second layer of shotcrete that was sprayed. This could have been done either to cover a bolt or to reduce water leakage. However, the presence of water is not enough for leaching to occur at this fast rate. The concrete must also be permeable to allow transportation of dissolved substances to the surface and it is possible that this is a secondary cause from water leakage. If water is present on the rock surface, the shotcretes ability to bond to the surface is affected and a possible solution is to increase the amount of accelerator. This makes the shotcrete stiffen faster but, as was shown by Lagerblad et al. [15], autogenous shrinkage in combination with the use of accelerators results in an increased porosity of the shotcrete. Furthermore, the effects of autogenous shrinkage increase for lower w/c ratios and cracks could have formed early due to insufficient curing. Since the bond between shotcrete and rock seemed intact, a fine pattern of cracks likely formed which could be one of the reasons to why no visible cracks were found. The other reason could be that these cracks have been healed through the leaching process. Even though it is known that wellcured concrete has a lower permeability it is unclear if sufficient curing would have been enough to prevent or decrease leaching when the concrete is subjected to an one-sided water pressure immediately after spraying. This is something that needs to be further investigated. 


\section{Laboratory tests}

The anticipated results from the experiment was an improved strength and a decreased water penetration for the samples that were water cured. Clearly, no such improvement can be seen based on the results presented in Figure 4. This could indicate four things:

- Adding water to a vertical surface during a limited time is inefficient and does not affect the water content in the shotcrete.

- The environmental conditions in the tunnel is such that natural curing is sufficient.

- Partial curing does not affect the development of strength.

- The test method is inappropriate to use to investigate the effects of partial curing.

It is likely that other curing methods, such as increasing the RH in the tunnel, are more efficient than spraying water on the ceiling and walls of the tunnel. Sprayed water on a vertical concrete surface drains off and it is possible that the effect of watering therefore is negligible. This effect could be tested in laboratory by comparing the strength of slabs that are cured in different positions. The effects of natural curing could also be tested by using a climate chamber. However, measurements of temperature and RH must first be conducted in the tunnel over a longer period so that daily variations could be understood. The drying conditions in the tunnel will be affected by the ventilation system and measurements should preferably be conducted at different locations to get an idea of the average conditions in the tunnel. It is possible that in-situ curing does not have any effect on the development of strength and that it is only important to cure the shotcrete to avoid cracks. Nevertheless, it was stated by Galan et al. [6] that natural curing might be insufficient to achieve a good surface strength. Experimental results presented in e.g. Neville [8] and by Chang et al. [11] show that the RH in only a part of the concrete will be affected by curing. Even though the change in $\mathrm{RH}$ in the concrete depends on many parameters, the presented results give an indication that the top surface $(30$ to $50 \mathrm{~mm}$ ) of the concrete is much more affected by curing than the rest. Therefore, it is clear that standard test methods are not appropriate to investigate the effects of curing. In the preparation of tests according to EN-14488-3 [20], the top part of the specimen is cut off. Furthermore, the bottom part of the slab which is least affected by curing is put in tension. In the light of this, the following change of test procedure is therefore proposed when investigating the effect of partial curing:

- The thickness of the specimen should be the same as the thickness of the rock support.

- Tests could be performed on beams sawn from slabs [20] or on round panels [23].

- After spraying, the top surface of slabs and panels should be smoothed to decrease the effects of stress concentrations implied by the irregular surface.

- Slabs and panels are cured under desired conditions.

- Beams or panels are tested by putting the top surface which is most affected by curing in tension.

\subsection{Bond strength testing}

It is well known that the shotcrete bond strength is affected by the type of rock, how well the surface is cleaned and that it is difficult to achieve a good strength if flowing water is present on the surface $[1,24]$. Due to all the influencing factors, it is difficult to make a direct comparison of results from different tunnels. Nevertheless, such comparisons give an indication of whether or not curing has any effect on the development of bond strength. The mean value for the bond 
strength presented here was $0.61 \mathrm{MPa}$ which could be compared to another part of the tunnel where it was $0.60 \mathrm{MPa}$. The tests in this paper was based on seven results while the other test was based on ten samples. For both tests, at least $80 \%$ of the fracture zone was located at the interface. Based on data from 354 tests done during the construction of a tunnel in the same region, Bjureland et al. [25] presented a mean value and standard deviation for bond strength between shotcrete and rock of $0.81 \mathrm{MPa}$ and $0.31 \mathrm{MPa}$, respectively. This indicates that sufficient bond strength in some cases can be achieved without curing.

Based on the previous discussion on curing, the interface should, especially when the shotcrete is thicker, be less affected by curing. Curing might therefore have no direct effect on the development of bond strength. However, this is something that needs to be further tested in laboratory. Curing has also an important indirect effect on the bond between shotcrete and rock and that is to prevent cracking during shrinkage. Previously, it has been shown that shrinkage could cause cracking and debonding of shotcrete, see e.g. Carlwsvärd [4] and Sjölander and Ansell [3]. Curing actions should therefore, if necessary, be undertaken to avoid cracking.

\section{CONCLUSIONS AND FURTHER RESEARCH}

In this paper, results from an in-situ and experimental investigation of the development of mechanical strength and presence of early cracks and leaching in shotcrete have been presented. It was concluded that even though large areas of precipitation existed, no visible cracks in the shotcrete could be found. On some locations, it is likely that leaching has occurred through cracks that either have been healed during the process or are too small to be visible. By comparing sections of leaching with geotechnical investigations of the rock prior to spraying of shotcrete, it was found that leaking water from grout holes or joints in the rock were present in some of the areas. The likely explanation to the extensive leaching is therefore that the grouting was unsuccessful which led to that water was present on the surface during spraying.

The mechanical strength of shotcrete with respect to partial curing for 48 hours was investigated in the tunnel. Results from laboratory testing showed no significant difference with respect to mechanical strength or water penetration. Even though the used curing method could be inefficient, the non-existing difference is believed to be a result of the used standard test method [20]. According to this, the top surface of the shotcrete, which is most affected by curing, is cut off in the process of preparing test specimens and the bottom side which is the least affected side by curing is put in tension. Therefore, modifications of the existing test standards have been suggested to enable studies on the effects of partial curing.

It is clear that if in-situ curing does not affect the strength or durability of the shotcrete it should be skipped to save time and money in the construction phase. Therefore, the next step in this investigation is to perform a new set of tests. This should be performed in a laboratory environment to have full control over the curing process and storing of the test samples. Furthermore, samples should be cured in a climate chamber to have full control over temperature and relative humidity and samples cured under water should be used as reference. The suggested improvements to the standards should be tested to determine if partial curing has any beneficial effects with regards to development of strength and durability of the shotcrete. If possible, a follow-up study should also include shotcrete specimens sprayed against rock to study if early curing, or the lack of it, increases the risk of plastic shrinkage cracking and de-bonding between shotcrete and rock. 


\section{ACKNOWLEDGEMENT}

The authors would like to thank Trafikverket (TRV) for the help to perform the in-situ investigation and the opportunity to plan and take part in the experimental work. Especially, the authors like to thank Nicklas Werner (TRV) and Safira Monteiro (former at TRV) for their help and commitment.

\section{REFERENCES}

1. Malmgren L, Nordlund E \& Rolund S: "Adhesion strength and shrinkage of shotcrete". Tunnelling and Underground Space Technology, Vol. 20, 2005, pp. 33-48.

2. Ansell A: "Investigation of shrinkage cracking in shotcrete on tunnel drains". Tunnelling and Underground Space Technology, Vol. 25, 2010, pp. 607-613.

3. Sjölander A \& Ansell A: "Numerical simulations of restrained shrinkage cracking in glass fibre reinforced shotcrete slabs". Advances in Civil Engineering, No. 8987626, 2017.

4. Carlswärd J: "Shrinkage cracking of steel fibre reinforced self-compacting concrete overlays: Test methods and theoretical modelling". PhD Thesis, Luleå University of Technology, Luleå, Sweden, 2006.

5. Ekström T: "Leaching of concrete: experiments and modelling". Report, Division of Building Materials, Lund University, Lund, Sweden, 2001.

6. Galan I, Baldermann A, Kusterle W, Dietzel M \& Mittermayr F: "Durability of shotcrete for underground support- Review and update". Construction and Building Material, 202, 2019, pp. 465-493.

7. Neville A M: "Properties of Concrete". Fifth Edition. Pearson Education Limited. Harlow, England, 2012.

8. Neville A M \& Brooks J J: "Concrete Technology". 2nd edition. Pearson Education Limited, Harlow, England, 2010.

9. Powers T: "A discussion of cement hydration in relation to the curing of concrete". Proceedings, Highway Research Board, Vol. 27, 1947, pp. 178-188.

10. CEN: "EN 13670: Execution of concrete structures". Technical report, Brussels, Belgium, 2009.

11. Zhang J, Wang J \& Gao Y: "Moisture movement in early-age concrete under cement hydration and environmental drying". Magazine of Concrete Research, Vol. 68, 2016, pp. 391-408.

12. Eriksson,D: "Numerical models for degradation of concrete in hydraulic structures due to long-term contact with water". Licentiate Thesis, Div. of Concrete Structures, Dept. of Civil \& Architectural Engineering, KTH Royal Institute of Technology, Stockholm, Sweden, 2017.

13. Van Tittelboom K \& de Belie N: "Self-healing in cementitious material - A review". Materials, Vol. 6, 2013, pp. 2182-2217.

14. Nijland T G, Larbi J A, van Hees R P J, Lubelli B \& de Rooij M: "Self healing phenomena in concretes and masonory mortars: A microscopic study". Proceedings, First International Conference on Self-Healing Materials, Noordwijk and Zee, The Netherlands, 2007.

15. Lagerblad B, Fjällberg L \& Vogt C: "Shrinkage and durability of shotcrete". Proceedings, Shotcrete Elements of a System, Queenstown 2010.

16. Trafikverket: "Rules for Tunnel Construction", TDOK 2016:0231, Trafikverket, Borlänge, Sweden, 2016. (In Swedish).

17. CEN: "EN-1992-1-1: Design of concrete structures - Part 1-1: General rules and rules for buildings". Technical report, Brussels, Belgium, 2008. 
Nordic Concrete Research - Publ. No. NCR 61 - ISSUE 2 / 2019 - Article 2, pp. 23-37

18. Boverket: "BFS 2013:10 EKS 9 - Swedish appendix to Eurocode", Boverket, Karlskrona, Sweden, 2013. (In Swedish).

19. CEN: "EN-12390-3: Testing hardening concrete - Part 3: Compressive strength of test specimens". Technical report, Brussels, Belgium, 2009.

20. CEN: "EN 14488-3: Testing sprayed concrete - Part 3: Flexural strengths". Technical report, Brussels, Belgium, 2006.

21. CEN: EN-12390-8: "Testing hardening concrete - Part 8: Depth of penetration of water under pressure". Technical report, Brussels, Belgium, 2019.

22. CEN: "EN-14488-4: 2005+A1:2008 Testing sprayed concrete - Part 4: Bond strength of cores by direct tension”. Technical report, Brussels, Belgium, 2008.

23. ASTM: "C1550-2: Standard test method for Flexural Toughness of Fiber Reinforced Concrete (Using Centrally Loaded Round Panels)". Technical report, American Society for Testing and Materials, USA, 2012.

24. Bryne L E, Ansell A \& Holmgren J: "Laboratory testing of early age bond strength of shotcrete on hard rock". Tunnelling and Underground Space Technology, Vol. 41, 2014, pp. 113-119.

25. Bjureland W, Johansson F, Sjölander A, Spross J \& Larsson S: "Probability distribution of shotcrete parameters for reliability-based analyses of rock tunnel support". Tunneling and Underground Space Technology, Vol. 87, 2019, pp. 15-26. 